\title{
Engenharia tecidual de cartilagem articular com ênfase em odontologia
} Articular cartilage tissue engineering with emphasis in dentistry

\author{
Estela Fernandes e Silva* \\ Karine Laste Macagnan* \\ Camila Perelló Ferrúa* \\ Rafaely Ferreira Severo* \\ Flávio Fernando Demarco ${ }^{* * *}$ \\ Fernanda Nedel ${ }^{* * * *}$
}

\section{Resumo}

Objetivo: revisar a literatura no que tange às fontes de células, scaffolds e agentes morfogênicos atualmente utilizados para a geração de cartilagem articular. Além disso, abordam-se os principais desafios para a geração de cartilagem funcional: propriedades mecânicas e lubrificantes. Revisão de literatura: a cartilagem articular é um tecido altamente especializado que reduz a fricção articular e distribui as forças relacionadas com elevadas cargas mecânicas entre as extremidades ósseas. Assim, traumas e certas doenças inflamatórias que afetam a cartilagem articular podem comprometer seriamente a qualidade de vida, causando dor e incapacitando o paciente. Nesse contexto, a engenharia tecidual é um campo emergente e multidisciplinar, cujos três componentes principais são: células responsivas, scaffolds e agentes morfogênicos. Considerações finais: os tratamentos atuais para o reparo de danos da cartilagem articular apresentam sérias limitações. Nesse sentido, a engenharia tecidual poderia contornar essas limitações pela geração de cartilagens substitutivas in vitro. Contudo, os componentes da tríade - células-tronco, agentes morfogênicos e scaffolds - necessitam de aperfeiçoamento antes da aplicação clínica. Além disso, deve-se considerar a aplicação de estímulos mecânicos e propriedades de superfície a fim de gerar uma cartilagem articular com características satisfatórias para a aplicação in vivo.

Palavras-chave: Condrócitos. Osteoartrite. Regeneração. Engenharia tecidual. Células-tronco.

\section{Revisão de literatura}

\section{Biologia da cartilagem articular}

As extremidades dos ossos longos dos mamíferos são cobertas por uma cartilagem articular que permite $o$ atrito e a distribuição de carga entre os $\operatorname{ossos}^{1}$. A estrutura própria da cartilagem fornece ao conjunto de tecidos, elementos necessários para suportar cargas, absorvendo impactos mecânicos e permitindo a movimentação. Essa cartilagem é um tecido conjuntivo, de consistência semirrígida, formado por um único tipo celular, os condrócitos. Em seres humanos, essas células correspondem a $1 \%$ do volume total do tecido, enquanto os $99 \%$ restantes são constituídos por uma matriz extracelular (MEC), altamente especializada, composta por: colágeno tipo II, proteoglicanos, proteínas não-colagenosas, glicoproteínas, água e eletrólitos dissolvidos ${ }^{2}$.

A MEC é composta, principalmente, por colágeno do tipo II, o que proporciona resistência à tração $0^{3}$, enquanto os proteoglicanos proporcionam resistência à compressão ${ }^{4}$. Subunidades proteoglicanos são chamados glicosaminoglicanos (GAGs), que formam as moléculas maiores chamadas agrecana ${ }^{5}$. Os condrócitos localizam-se em lacunas no interior da cartilagem e sintetizam os compostos necessários à manutenção da MEC, além de a estabilizarem.

\footnotetext{
Graduandas, Centro de Biotecnologia, Universidade Federal de Pelotas, Pelotas, RS, Brasil.

Doutoranda do Programa de Pós-graduação em Saúde e Comportamento, Universidade Católica de Pelotas, Pelotas, RS, Brasil.

* Professor, Programa de Pós-graduação em Odontologia, Universidade Federal de Pelotas, Pelotas, RS, Brasil.

*** Professora, Programa de Pós-graduação em Saúde e Comportamento, Universidade Católica de Pelotas, Pelotas, RS, Brasil.
} 
A MEC está organizada em quatro zonas: superficial, média, profunda e calcificada. A organização em zonas específicas bem como a nanoarquitetura da MEC contribuem para geração das propriedades viscoelásticas ${ }^{6}$.

A nutrição dos condrócitos dá-se por meio de uma barreira de difusão, em condições de anaerobiose $^{4}$. Devido à natureza avascular desse tecido, a nutrição ocorre por meio da difusão de substâncias oriundas dos capilares do tecido conjuntivo fibroso que envolve todo tecido cartilaginoso, chamada pericôndrio.

No tecido cartilaginoso adulto normal, para manter uma condição estável da matriz, faz-se necessária a regulação do ambiente interno. $\mathrm{O}$ balanceamento acontece por meio de diversos fatores de crescimento, de forma que não ocorra ganho ou perda de tecido. Dentre os fatores de crescimento envolvidos podem ser citados dois deveras relevantes, o fator de crescimento semelhante à insulina-1 (IGF1) e o fator de transformação de crescimento-beta (TGF-b). Ambos estimulam a síntese de agrecana e de colágeno; além das citocinas como interleucina-1 (IL-1), a interleucina-6 (IL-6) e o fator de necrose tumoral alfa (FNT- $\alpha$ ), que estimulam a degradação da matriz?

\section{Lesões e tratamentos}

Haja vista que o tecido cartilaginoso articular é responsável por absorver impactos mecânicos, as lesões que acometem essa estrutura podem agregar aspectos negativos quanto à qualidade de vida dos pacientes. Essas lesões podem se desenvolver a partir da prática esportiva, de acidentes automobilísticos ou por outros traumas. Além disso, a cartilagem articular também pode ser acometida por doenças inflamatórias reumáticas que afetam pessoas de todas as idades e sexos, com causas e cura ainda desconhecidas 8,9 .

Uma das mais relevantes doenças inflamatórias reumáticas é a osteoartrite (OA), que afeta mais de 200 milhões de pessoas em todo o mundo, só na Europa, 350.000 cirurgias artroscópicas são realizadas anualmente ${ }^{10}$. Nota-se, assim, que qualquer agente causador de danos à cartilagem articular é deveras importante e deve ser excluído ou minimizado, uma vez que, devido à sua natureza avascular, o tecido cartilagino tem regeneração limitada ${ }^{11,12}$.

Nesse âmbito, inúmeros tratamentos visam contornar o comprometimento da cartilagem articular. Dentre as opções de tratamento, tem-se como alternativa a substiuição do tecido cartilaginoso lesado por um tecido autógeno, trata-se de uma técnica promissora por evitar rejeição imunológica e transmissão de doenças. Contudo, esses tratamentos podem apresentar limitações, como a baixa resistência mecânica do tecido substituinte.

Existem outras opções para sanar ou minimizar as complicações que afetam tecidos cartilaginosos, como o aloenxerto e o xenoenxerto, esse em menor grau, devido à limitação da imunogenicidade, que pode levar à imunorrejeição. Dessa forma, muitos tratamentos são paleativos e restringem-se à eliminação da dor. Assim, o "padrão-ouro" no tratamento continua sendo a substituição total da articulação, que, embora bem sucedida, tem uma vida útil de aproximadamente dez a quinze anos.

Logo, a grande incidência e o carácter nocivo da degeneração de cartilagem mostram-se como indicadores para o desenvolvimento da engenharia de tecidos $(\mathrm{ET})^{13,14}$. Portanto, a presente revisão irá abordar as principais fontes de células, tipos de scaffolds e agentes morfogênicos pesquisados na atualidade para o desenvolvimento de cartilagem a partir da ET. Finalmente, abordará os principais desafios para geração de cartilagens funcionais: propriedades mecânicas e lubrificantes.

\section{Engenharia tecidual: aspectos importantes}

A engenharia de tecidos trata-se de um novo campo da ciência, que tem como objetivo reconstruir ou restaurar tecidos vivos. Devido ao seu caráter multidisciplinar, faz-se necessário sumarizar sua complexidade por meio de uma tríade, que contém elementos básicos que atuam como pilares para a geração dos tecidos biológicos: células responsivas, scaffolds e agentes morfogênicos ${ }^{5}$.

No entanto, sem o aporte sanguíneo, um tecido criado pela ET, poderá apresentar dificuldades no seu desenvolvimento no sítio de reparo. A vascularização é de suma importância, visto que é responsável pelo abastecimento das células com $\mathrm{O}_{2}$ e nutrientes, e excreção de $\mathrm{CO}_{2}$ e outros metabólitos. Possibilita a sobrevivência, a funcionalidade, a organização estrutural e a interação entre tecido recém-formado e área lesada ${ }^{15}$.

Para o sucesso da ET, a grande maioria dos tecidos do organismo depende de um sistema de vasos sanguíneos ramificados, com distanciamento ideal menor que $200 \mu \mathrm{m}$. Todavia, a cartilagem bem como a córnea e a pele são tecidos que podem ser suplementados com nutrientes e $\mathrm{O}_{2}$ advindos de uma rede de vasos sanguíneos próximos por meio de difusão, justificando assim o possível sucesso da ET em áreas de reconstrução em pele e cartilagem ${ }^{16}$.

\section{Células responsivas}

Células responsivas são células sensíveis à sinalização que podem ser obtidas a partir de abordagens básicas. Um dos métodos de obtenção é o modo autólogo, no qual, por meio de uma biopsia, obtêm-se células órgão-específicas. Essa técnica se aplica à maioria dos órgãos, contudo, para alguns tecidos ou órgãos, como válvulas cardíacas, a biópsia direta não é uma alternativa viável. 
Existe, contudo, outra opção para a obtenção de células responsivas, que consiste no isolamento de células-tronco embrionárias ou adultas, uma vez que elas têm a capacidade de diferenciar-se em diversos tipos celulares. Todavia, deve-se compreender o correto mecanismo de indução à diferenciação e controle para o tipo de célula desejável. Ainda, a utilização de célula-tronco embrionária encontra limitações éticas devido à utilização das células da massa interna do blastocisto, que leva à destruição do blastocisto e, por conseguinte, à incapacidade de gerar vida ${ }^{15}$.

Dessa forma, pesquisas recentes focam-se na obtenção de células-tronco adultas, como as do tecido pulpar de dentes decíduos ${ }^{17}$ e permanentes ${ }^{18}$, no entanto, sabe-se que essas não são as únicas fontes dentro da cavidade bucal. Podem-se encontrar também células-tronco no ligamento periodontal ${ }^{19}$ e na papila apical de dentes não totalmente desenvolvi$\operatorname{dos}^{20}$.

Também na tentativa de contornar questões éticas acerca da utilização de embriões humanos e problemas relacionados à imunorrejeição, as células-tronco pluripotentes induzidas (CTPIs) foram desenvolvidas. A geração dessas células baseia-se na transformação de células diferenciadas em células-tronco semelhantes a células embrionárias por meio da inserção de uma série de fatores de transcrição no genoma, a fim de converter o estado transcricional e epigenético em um estado de pluripotência ${ }^{21}$.

\section{Scaffolds}

Os scaffolds são estruturas tridimensionais po$\operatorname{rosas}^{22}$ que propiciam um microambiente adequado para o crescimento e a diferenciação celular, promovendo adesão e migração das células ${ }^{23}$. Durante 0 desenvolvimento de certos tecidos por ET, pode-se fazer uso de scaffolds que se degradam lenta e progressivamente após a implantação ${ }^{24}$, ou scaffolds não biodegradáveis, confeccionadas, por exemplo, à base de titânio ${ }^{25}$. Salienta-se que essas estruturas devem apresentar características ambientais que induzam a reconstrução tecidual por meio da interação das células selecionadas com a superfície de adesão do scaffold e com outras células existentes no microambiente, e/ou com a incorporação de fatores de crescimento ${ }^{26}$.

\section{Agentes morfogênicos}

Os agentes morfogênicos, também chamados de fatores de crescimento, são proteínas solúveis que atuam na proliferação celular, síntese de matriz e diferenciação tecidual. Eles podem ter ação mitogênica, sendo responsáveis pela proliferação de determinados tipos celulares, ou ação morfogênica, quando comanda alterações do fenótipo de células-alvo. Pode-se afirmar que seus efeitos são mediados por receptores de superfície das células-alvo, como fatores de crescimento derivados das plaquetas (PDGF), similares a IGFs, TGF- $\beta$ e proteínas ósseas morfogenéticas (BMPs) ${ }^{27,28}$.

$\mathrm{Na}$ odontologia, destaca-se um grupo de fatores de crescimento, o das BMPs, que estão presentes nos extratos indutores da matriz óssea. Corroborando com os resultados positivos advindos da ET, as BMPs contribuem de forma significativa no aumento do reparo ósseo ${ }^{29}$ de lesões no palato e na mandíbula ${ }^{30}$.

\section{Angiogênese}

A angiogênese consiste na formação de novos vasos sanguíneos. É um mecanismo essencial para o crescimento, o reparo e a cicatrização de tecidos. A angiogênese contribui diretamente para o sucesso da ET, haja vista que é dependente da vascularização dos enxertos produzidos ${ }^{10}$. Assim, para que o tecido criado por ET receba aporte sanguíneo, é preciso que os vasos sanguíneos sejam funcionais e que se anastomosem com o sistema vascular do hospedeiro, fato que é um dos grandes desafios nessa área ${ }^{31}$.

A neovascularização, por sua vez, é um evento crítico, pois as células podem permanecer vivas por difusão somente quando estão próximas a um suprimento de sangue ${ }^{32}$. Para induzir a neovascularização de tecidos hipóxicos, pode-se utilizar uma abordagem de administração de fatores de crescimento pró-angiogênicos, como o fator de crescimento vascular endotelial (VEGF) ${ }^{33}$. Contudo, no que diz respeito à angiogênese, a geração de cartilagem articular não é um entrave significativo, pois diferente de outros tipos de tecidos essa estrutura mostra-se avascular ${ }^{10}$.

\section{Engenharia tecidual para obtenção de cartilagem articular: atualidade}

\section{Fonte de células responsivas}

A fonte ideal de células para a engenharia de cartilagem é aquela que pode ser facilmente isolada e ampliada, em cultivo in vitro, e que sintetiza abundantes componentes específicos de MEC, como agrecana e colágeno tipo II. Dessa forma, as células mais estudadas para essa finalidade são os condrócitos e as células-tronco ${ }^{34}$.

\section{Condrócitos}

Os condrócitos são células capazes de produzir, manter e remodelar a MEC da cartilagem ${ }^{35,36}$. Essas células podem ser utilizadas em tratamentos de algumas desordens de saúde, pois são capazes de re- 
parar de forma eficaz defeitos articulares ${ }^{37}$. No entanto, algumas desvantagens são observadas, como a falta de disponibilidade de condrócitos autólogos e a diminuição da funcionalidade de células coletadas nas articulações de pacientes doentes. Além disso, condrócitos cultivados em monocamadas sofrem desdiferenciação, caracterizada pela diminuição da síntese de proteoglicanos e expressão de colágeno do tipo II e aumento de expressão de colágeno tipo $\mathrm{I}^{35,36}$.

A idade do doador dos condrócitos exerce influência no cultivo in vitro ${ }^{1}$. Condrócitos de jovens doadores demonstram proliferação mais rápida e potencial condrogênico aumentado em relação a condrócitos de doadores mais velhos, sendo essas células metabolicamente menos ativas in vitro ${ }^{38}$. Essas limitações podem ser parcialmente compensadas com a condição de cultivo, como utilização de biorreatores ${ }^{39}$, tensão de oxigênio reduzida ${ }^{40}$ e adição de fatores de crescimento $^{41}$. No entanto, o uso dessas células para reparar a cartilagem não parece favorável.

Um aspecto desfavorável para a utilização dessas células é o fato de que, por exemplo, os condrócitos costais (CC) por si só não são capazes de atenuar a ossificação do tecido cartilaginoso. Contudo, com o cocultivo de $\mathrm{CC}$ e de células-tronco da polpa de dentes permanentes (DPSCs) na presença do fator de crescimento fibroblástico-9 (FGF-9), é possivel aperfeiçoar a diferenciação das DPSCs em tecido cartilaginoso e inibir parcialmente a sua mineralização ${ }^{37}$.

\section{Células-tronco}

Uma possível solução para superar a oferta limitada de condrócitos é a utilização de células-tronco multipotentes, principalmente células com origem na medula óssea e no tecido adiposo.

As células-tronco derivadas da medula óssea (BMSCs) podem ser facilmente obtidas e induzidas a se diferenciar em cartilagem, para posterior expansão in vitro ${ }^{8}$. As células-tronco derivadas de tecido adiposo (ADSCs) são capazes de se diferenciar em condrócitos, utilizando sistemas de cultivo 3D na presença de ácido ascórbico, dexametasona e TGF- $\beta^{42}$. Embora estudos apontem a produção de componentes da matriz bem como o aumento de propriedades mecânicas, destaca-se que o potencial condrogênico é menor se comparado com BMSCs.

Neste contexto, a melhor compreensão dos mecanismos moleculares que regulam a diferenciação mostra-se essencial. Bobick et al. ${ }^{9}$ (2010) relataram pela primeira vez que as vias de sinalização ERK5 e ERK1/2 (proteínas quinase ativadas por mitógenos) desempenham papéis opostos na regulação da condrogênese de BMSCs. Desse modo, a via de sinalização ERK5 mostra-se como regulador negativo da formação de cartilagem, enquanto a via ERK1/2 mostra-se como regulador positivo ${ }^{9}$.

\section{Agentes morfogênicos}

Diversas citocinas, hormônios e fatores de crescimento podem influenciar os processos anabólicos e catabólicos dos condrócitos. Portanto, um grande número de fatores de crescimento, incluindo TGF- $\beta$, IGF-1, BMPs e, em menor grau, FGFs e fator de crescimento epidérmico (EGF), tem sido utilizado em estudos de ET de cartilagem in vitro para promover o fenótipo condrogênico, estimular a produção de MEC e promover condrogênese de células-tronco mesenquimais $(\mathrm{CTM} s)^{43}$.

Diferentes isoformas de TGF- $\beta$ desempenham um papel importante no desenvolvimento e reparo da cartilagem, principalmente as isoformas TGF- $\beta 1$, 2 e 3, que aumentam a proliferação de condrócitos e a síntese de MEC pelos condrócitos. Além disso, o TGF- $\beta 1$ e 3 promovem a condrogênese de CTMs ${ }^{44,45}$.

Outro estudo corrobora os achados anteriores e aponta que a interação celular de CTMs na forma de cultivo em micromassas (células dissociadas que são reagregadas em esferoides, evitando a utilização de scaffold) pode regular a proliferação e diferenciação das CTMs do periósteo durante condrogênese, e que este efeito é reforçado quando na presença de TGF- $\beta 3^{46}$.

O IGF-1 pode estimular a atividade anabólica de condrócitos e induzir à condrogênese de $\mathrm{CTM}^{47}$. As BMPs, especialmente BMP-2 e BMP-7, promovem também a condrogênese de CTMs e aumentam a produção de MEC pelos condrócitos e $\mathrm{CTMs}^{3}$. Assim, uma combinação de fatores de crescimento nas culturas de condrócitos e CTMs in vitro pode potencializar os efeitos sobre essas células ${ }^{48}$.

No entanto, o efeito da aplicação de moléculas de sinalização não é apenas dependente do tipo de fator que é aplicado. Outros parâmetros também estão envolvidos, como a dose, o tempo de administração e o tipo de célula em que atuam ${ }^{49}$.

\section{Scaffolds}

Quando, por meio da ET, tenta-se reestabelecer um tecido cartilaginoso, a técnica baseia-se em cultivar os condrócitos em uma matriz artificial, biodegradável, que possa suportar o crescimento da cartilagem durante alguns meses, enquanto os condrócitos e a MEC se estabelecem, sem alterações fenotípicas. O scaffold, por sua vez, degrada-se gradualmente, em oito a dez semanas após o implante de cartilagem ${ }^{50}$.

Diferentes sistemas de cultura são usados na expansão dos condrócitos: a cultura de condrócitos em monocamadas ${ }^{4}$ e a cultura em sistema tridimensional em esponjas de colágeno, fibrina, gel de agarose, hidrogel de alginato, quitosana, etc ${ }^{1}$. 


\section{Polímeros naturais}

Os polímeros naturais podem ser classificados, quanto à constituição, em proteínas, como fibrina e colágeno, e em carboidratos, como agarose, alginato, ácido hialurônico e quitosana. Muitos desses são hidrogéis, o que os torna apropriados para a engenharia de cartilagem que tem alto conteúdo de água. A característica mais atrativa de hidrogéis é que as células encapsuladas em scaffolds conseguem manter seu fenótipo de condrócitos esféricos e não desdiferenciam ${ }^{51}$.

Além disso, uma nova perspectiva é a incorporação de nano e microfibras de titânio e de hidroxiapatita em hidrogéis de alginato. Esse método proporciona um scaffold com características físicas melhoradas e, concomitantemente, gera um ambiente mais adequado para adesão e proliferação celular ${ }^{52}$. Não obstante, os scaffolds à base de hidrogel são também interessantes para estudos que empregam carga mecânica, pois são capazes de transduzi-la, de modo que as forças podem ser exercidas sobre as células ${ }^{51}$.

\section{Polímeros sintéticos}

Os polímeros sintéticos mais utilizados em scaffolds são os poli-hidroxi- $\alpha$-ésteres, especialmente o ácido polilático (PLA) e o ácido poliglicólico (PGA), devido à sua biodegradabilidade. Scaffolds feitos à base de polímeros sintéticos, quando comparados com hidrogéis, apresentam melhor resistência mecânica ${ }^{53}$. Além disso, as propriedades dos scaffolds sintéticos podem ser alteradas, permitindo ajustar, por exemplo, a taxa de degradação, suas características estruturais e de resistência mecânica. Em contrapartida, uma desvantagem dos polímeros sintéticos é que as células muitas vezes não mantêm seu fenótipo normal e produzem MEC com propriedades inferiores em relação aos scaffolds à base de polimeros naturais ${ }^{54}$.

\section{Arquitetura, porosidade e rigidez}

A porosidade, o tamanho dos poros e a interconectividade do scaffold são propriedades importantes, uma vez que influenciam a migração celular e a difusão de oxigênio, nutrientes, produtos residuais e moléculas de sinalização $0^{55}$. Por exemplo, a oferta de oxigênio não homogênea da periferia ao centro da cultura pode levar à morte celular nas regiões centrais $^{56}$.

Além disso, um material poroso melhora mecanicamente a relação entre o implante e a cartilagem natural, proporcionando uma maior estabilidade mecânica na interface. Tem sido observado que o tamanho ideal dos poros para promover a proliferação é entre $100 \mathrm{~mm}$ e $500 \mathrm{~mm}^{57}$.

A rigidez dos scaffolds também influencia na diferenciação e no crescimento das células em cul- tura de tecidos. $\mathrm{O}$ aumento da rigidez influencia na morfologia dos condrócitos, que passa de uma forma arredondada com actina nebulosa e substratos mais fracos a uma forma predominante com morfologia plana, com fibras de actina sobre estresse e substratos mais rígidos ${ }^{58}$.

\section{Odontologia e tecido cartilaginoso}

Quando os tópicos odontologia e tecido cartilaginoso são abordados concomitantemente, duas questões podem surgir: como reabilitar pacientes com desordens no disco cartilaginoso da articulação temporomandibular (ATM) e como os tecidos bucais podem servir de fonte celular para criar tecido cartilaginoso.

Cabe destacar que as desordens na ATM comprometem a porção cartilaginosa do côndilo e dão origem a novas investigações na área da ET, que busca sanar o desafio de reconstruir cartilagem e minimizar defeitos cartilaginosos ${ }^{59}$. Assim, estudos em modelo animal mostram que é possível reconstituir, em poucos meses, todos os elementos da cartilagem condilar ${ }^{60}$. Discos substitutos foram gerados a partir de ET, utilizando scaffolds altamente porosos e biorreabsorvíveis, semeados com condrócitos. Após doze semanas foi obtida uma neocartilagem, que mostrou evidências histológicas de cartilagem hialina organizada ${ }^{61}$.

Também, não menos importante, vale ressaltar que a cavidade oral tem múltiplos sítios fontes de células-tronco, como o tecido pulpar de dentes decíduos $^{17}$ e permanentes ${ }^{18}$, o ligamento periodontal ${ }^{19}$ e a papila apical de dentes não totalmente desenvolvidos ${ }^{20}$. Dentre essas células, destacam-se as de origem pulpar, já que os dentes são facilmente obtidos por motivos ortodônticos, periodontais, cárie e exfoliação natural de decíduos ${ }^{62}$. Além disso, essas células possuem a capacidade de diferenciação em tecido condrogênico ${ }^{63,64}$.

As CTMs, por sua vez, possuem capacidade de migração e diferenciação, além de participarem da morfogênese de alguns tecidos, como o cartilaginoso. Mesmo passado o período de morfogênese essas células, com características de células-tronco adultas, seguem com capacidade de diferenciar-se e podem contribuir ativamente no reparo de lesões, favorecendo a regeneração tecidual ${ }^{65}$. Dessa forma, um estudo recente, utilizando CTMs de origem bucal, mostra que com um microambiente favorável e sinais indutivos é possível diferenciar essas células em tecido condrogênico com características de viabilidade $^{66}$.

\section{Conclusão}

Os tratamentos atuais para o reparo de danos da cartilagem articular apresentam sérias limitações. Nesse âmbito, a engenharia de tecidos poderia 
contornar essas limitações pela geração de cartilagens substitutivas in vitro. Contudo, os componentes da tríade necessitam de aperfeiçoamento antes da aplicação clínica. Com isso, acredita-se que as células-tronco multipotentes são promissoras em relação à disponibilidade, porém faz-se necessário elucidar mecanismos de geração da MEC.

Além disso, os scaffolds de polímeros sintéticos mostram-se vantajosos por facilitarem o controle das propriedades de carga e degradação, entretanto, muitas vezes são incapazas de manter o fenótipo dos condrócitos. Quanto aos agentes morfogênicos, inúmeros aspectos devem ser considerados e adaptados ao tipo de célula cultivada, como o tipo de agente, sua concentração e tempo de exposição. Finalmente, além de contornar as limitações dos componentes da tríade, deve-se considerar a aplicação de estímulos mecânicos e propriedades de superfície a fim de gerar uma cartilagem articular com características satisfatórias para a aplicação in vivo.

\section{Abstract}

Objective: To review the literature regarding sources of cells, scaffolds, and morphogenic agents currently used to produce articular cartilage. In addition, to address the main challenges for the production of functional cartilage: mechanical and lubricant properties. Literature review: The articular cartilage is a highly specialized tissue that reduces joint friction and distributes forces related to high mechanical loads between bone ends. Thus, trauma and certain inflammatory diseases that affect the articular cartilage may severely compromise quality of life, causing pain and disability. In this context, tissue engineering is an emerging and multidisciplinary field, which three main components are responsive cells, scaffolds, and morphogenic agents. Final considerations: Current treatments for articular cartilage repair have major limitations. Accordingly, tissue engineering could overcome these limitations by producing in vitro cartilage substitutes. However, the triad components - stem cells, morphogenic agents, and scaffolds - need further improvement before clinical application. Moreover, one should consider the application of mechanical stimuli and surface properties to produce an articular cartilage with satisfactory characteristics for in vivo application.

Keywords: Chondrocytes. Osteoarthritis. Regeneration. Tissue engineering. Stem cells.

\section{Referências}

1. Hunziker EB. Articular cartilage repair: basic science and clinical progress. A review of the current status an prospects. Osteoarthr Cartil 2001; 10:432-63.

2. Kisiday JD, Jin M, DiMicco MA, Kurz B, Grodzinsky AJ. Effects of dynamic compressive loading on chondrocyte biosynthesis in self-assembling peptide scaffolds. J Biomech 2004; 37(5):595-604.

3. Kurth T, Hedbom E, Shintani N, Sugimoto M, Chen FH, Haspl M et al. Chondrogenic potential of human synovial mesenchymal stem cells in alginate. Osteoarthritis Cartilage 2007; 15(10):1178-89.

4. Hauselmann HJ, Fernandes RJ, Mok SS, Schmid TM, Block JA, Aydelotte MB et al. Phenotypic stability of bovine articular chondrocytes after long-term culture in alginate beads. $J$ Cell Sci 1994; 107(Pt 1):17-27.

5. Langer R, Vacanti JP. Tissue Engineering Science 1993; 260(5110):920-6.

6. Kock LM, Schulz RM, Van Donkelaar CC, Thummler CB, Bader A, Ito K. RGD-dependent integrins are mechanotransducers in dynamically compressed tissue-engineered cartilage constructs. J Biomech 2009; 42:2177-82.

7. Rezende UM, Hernandez AJ, Camanho GL, Amatatuzzi MM. Cartilagem articular e osteoartrose. Acta Orthop Bras 2000; 8:100-4.

8. Boeuf S, Richter W. Chondrogenesis of mesenchymal stem cells: role of tissue source and inducing factors. Stem Cell Res Ther 2010; 1(4):31.

9. Bobick BE, Matsche AI, Chen FH, Tuan RS. The ERK5 and ERK1/2 signaling pathways play opposing regulatory roles during chondrogenesis of adult human bone marrowderived multipotent progenitor cells. J Cell Physiol 2010; 224(1):178-86.

10. Bartold PM, Xiao Y, Lyngstadaas SP, Paine ML, Snead ML. Princípios e aplicações dos sistemas de liberação celular para a regeneração periodontal. Periodontol 2008; (15):12335.

11. Ross MH, Kaye GI, Pawlina W. Cartilage. Histology: A text and atlas with cell and molecular biology. 4. ed. Philadelphia: Lippincott Williams \& Wilkins; 2003. p. 164-79.

12. Tuan RS, Chen FH. Cartilage. In: Battler A, Leor J, editors. Stem cell and gene-based therapy: Frontiers in regenerative medicine. London: Springer; 2006. p. 179-93.

13. Revell CM, Athanasiou KA. Success rates and immunologic responses of autogenic, allogenic, and xenogenic treatments to repair articular cartilage defectst. Tissue Eng Part B Rev 2008; 15(1):1-15.

14. Samuels J, Krasnokutsky S, Abramson SB. Osteoarthritis: a tale of three tissues. Bull NYU Hosp Jt Dis 2008; 66(3):244-50.

15. Nedel F, Andre D de A, de Oliveira IO, Cordeiro MM, Casagrande L, Tarquinio SB et al. Stem cells: therapeutic potential in dentistry. J Contemp Dent Pract 2009; 10(4):90-6.

16. Novosel EC, Kleinhans C, Kluger PJ. Vascularization is the key challenge in tissue engineering. Adv Drug Deliv Rev 2011; 63(4-5):300-11.

17. Miura M, Gronthos S, Zhao M, Lu B, Fisher LW, Robey PG et al. SHED: stem cells from human exfoliated deciduous teeth. Proc Natl Acad Sci USA 2003; 100(10):5807-12.

18. Gronthos S, Mankani M, Brahim J, Robey PG, Shi S. Postnatal human dental pulp stem cells (DPSCs) in vitro and in vivo. Proc Natl Acad Sci USA 2000; 97(25):13625-30.

19. Seo BM, Miura M, Gronthos S, Bartold PM, Batouli S, Brahim $J$ et al. Investigation of multipotent postnatal stem cells from human periodontal ligament. Lancet 2004; 364(9429):149-55.

20. Yamanaka S, Takahashi K. Induction of pluripotent stem cells from mouse fibroblast cultures. Tanpakushitsu Kakusan Koso 2006; 51(15):2346-51.

21. Stock UA, Vacanti JP. Tissue engineering: current state and prospects. Ann Rev Med 2001; 52:443-51.

22. Nakashima M. Bone morphogenetic proteins in dentin regeneration for potential use in endodontic therapy. Cytokine Growth Factor Rev 2005; (3):369-76.

23. Atala A. Engineering tissues, organs and cells. J Tissue Eng Regen Med 2007; 1(2):83-96. 
24. Warnke PH, Springer IN, Wiltfang J, Acil Y, Eufinger $\mathrm{H}$, Wehmoller $\mathbf{M}$ et al. Growth and transplantation of a custom vascularised bone graft in a man. Lancet 2004; 364(9436):766-70.

25. Bartold PM, McCulloch CA, Narayanan AS, Pitaru S. Tissue engineering: a new paradigm for periodontal regeneration based on molecular and cell biology. Periodontol 2000; 24:253-69.

26. Schlienphake H. Bone growth factors in maxillofacial skeletal reconstruction. Int J Oral Maxillofac Surg 2002; 31(5):469-84.

27. Smith AJ. Vitality of the dentin-pulp complex in health and disease: growth factors askey mediators. J Dent Educ 2003; 67(6):678-689.

28. Wozney JM. Overview of bone morphogenetic proteins. Spine (Phila Pa 1976) 2002; 27(16 Suppl 1):S2-8.

29. Chenard KE, Teven CM, He TC, Reid RR. Bone morphogenetic proteins in craniofacial surgery: current techniques, clinical experiences, and the future of personalized stem cell therapy. J Biomed Biotechnol 2012; 601549.

30. Cordeiro MM, Dong Z, Kaneko T, Zhang Z, Miyazawa M, Shi $\mathrm{S}$ et al. Dental pulp tissue engineering with stem cells from exfoliated deciduous teeth. J Endod 2008; 34(8):962-9.

31. Bujia J, Sittinger M, Minuth WW, Hammer C, Burmester G, Kastenbauer E. Engineering of cartilage tissue using bioresorbable polymer fleeces and perfusion culture. Acta Otolaryngol 1995; 115(2):307-10.

32. Grando Mattuella L, Westphalen Bento L, de Figueiredo JA, Nor JE, de Araujo FB, Fossati AC. Vascular endothelial growth factor and its relationship with the dental pulp. $J$ Endod 2007; 33(5):524-30.

33. Chung C, Burdick JA. Engineering cartilage tissue. Adv Drug Deliv Rev 2008; 60(2):243-62.

34. Goessler UR, Bugert P, Bieback K, Baisch A, Sadick $\mathrm{H}$, Verse $\mathrm{T}$ et al. Expression of collagen and fiber-associated proteins in human septal cartilage during in vitro dedifferentiation. Int $\mathrm{J}$ Mol Med 2004; 14(6):1015-22.

35. Goessler UR, Bieback K, Bugert P, Naim R, Schafer C, Sadick $\mathrm{H}$ et al. Human chondrocytes differentially express matrix modulators during in vitro expansion for tissue engineering. Int J Mol Med 2005; 16(4):509-15.

36. Dai J, Wang J, Lu J, Zou D, Sun H, Dong Y et al. The effect of co-culturing costal chondrocytes and dental pulp stem cells combined with exogenous FGF9 protein on chondrogenesis and ossification in engineered cartilage. Biomaterials 2012; 33(31):7699-711.

37. Dehne T, Karlsson C, Ringe J, Sittinger M, Lindahl A. Chondrogenic differentiation potential of osteoarthritic chondrocytes and their possible use in matrix-associated autologous chondrocyte transplantation. Arthritis Res Ther 2009; 11(5):R133

38. Marlovits S, Tichy B, Truppe M, Gruber D, Vecsei V. Chondrogenesis of aged human articular cartilage in a scaffold-free bioreactor. Tissue Eng 2003; 9(6):1215-26.

39. Foldager CB, Nielsen AB, Munir S, Ulrich-Vinther M, Soballe $\mathrm{K}$, Bunger $\mathrm{C}$ et al. Combined $3 \mathrm{D}$ and hypoxic culture improves cartilage-specific gene expression in human chondrocytes. Acta Orthop 2011; 82(2):234-40.

40. Terada S, Fuchs JR, Yoshimoto H, Fauza DO, Vacanti JP. In vitro cartilage regeneration from proliferated adult elastic chondrocytes. Ann Plast Surg 2005; 55(2):196-201.

41. Estes BT, Guilak F. Three-dimensional culture systems to induce chondrogenesis of adipose-derived stem cells. Methods Mol Biol 2011; 702:201-17.
42. Ahmed TA, Hincke MT. Strategies for articular cartilage lesion repair and functional restoration. Tissue Eng Part B Rev 2010; 16(3):305-29.

43. Puetzer JL, Petitte JN, Loboa EG. Comparative review of growth factors for induction of three-dimensional in vitro chondrogenesis in human mesenchymal stem cells isolated from bone marrow and adipose tissue. Tissue Eng Part B Rev 2010; 16(4):435-44.

44. Xu J, Wang W, Ludeman M, Cheng K, Hayami T, Lotz JC et al. Chondrogenic differentiation of human mesenchymal stem cells in three-dimensional alginate gels. Tissue Eng Part A 2008; 14(5):667-80.

45. Mara CS, Sartori AR, Duarte AS, Andrade AL, Pedro MA, Coimbra IB. Periosteum as a source of mesenchymal stem cells: the effects of TGF-beta3 on chondrogenesis. Clinics (São Paulo) 2011; 66(3):487-92.

46. Mara CS, Sartori AR, Duarte AS, Andrade ALL, Pedro MA, Coimbra IB. Periosteum as a source of mesenchymal stem cells: the effects of TGF-B3 on chondrogenesis. Clinics 2011; 66(3):487-92.

47. Yoon DM, Fisher JP. Effects of exogenous IGF-1 delivery on the early expression of IGF-1 signaling molecules by alginate embedded chondrocytes. Tissue Eng Part A 2008; 14(7):1263-73

48. Chua KH, Aminuddin BS, Fuzina NH, Ruszymah BH. Interaction between insulin-like growth factor-1 with other growth factors in serum depleted culture medium for human cartilage engineering. Med J Malaysia 2004; 59 (Suppl B):7-8.

49. Byers BA, Mauck RL, Chiang IE, Tuan RS. Transient exposure to transforming growth factor beta 3 under serumfree conditions enhances the biomechanical and biochemical maturation of tissue-engineered cartilage. Tissue Eng Part A 2008; 14(11):1821-34.

50. Bentley G, Minas T. Revisão clínica: tratar a lesão articular em jovens. Br Med J 2001; 10

51. Spiller KL, Maher SA, Lowman AM. Hydrogels for the repair of articular cartilage defects. Tissue Eng Part B Rev 2011; 17(4):281-99.

52. Santana BP, Paganotto GF, Nedel F, Piva E, de Carvalho RV, Nor JE et al. Nano-/microfiber scaffold for tissue engineering: physical and biological properties. J Biomed Mater Res A 2012; 100(11):3051-8.

53. 53. Munirah S, Kim SH, Ruszymah BH, Khang G. The use of fibrin and poly(lactic-co-glycolic acid) hybrid scaffold for articular cartilage tissue engineering: an in vivo analysis. Eur Cell Mater 2008; 15:41-52.

54. Chen G, Sato T, Ushida T, Hirochika R, Shirasaki Y, Ochiai $\mathrm{N}$ et al. The use of a novel PLGA fiber/collagen composite web as a scaffold for engineering of articular cartilage tissue with adjustable thickness. J Biomed Mater Res A 2003; 67(4):1170-80.

55. Nuernberger S, Cyran N, Albrecht C, Redl H, Vecsei V, Marlovits S. The influence of scaffold architecture on chondrocyte distribution and behavior in matrix-associated chondrocyte transplantation grafts. Biomaterials 2011; 32(4):1032-40.

56. Volkmer E, Drosse I, Otto S, Stangelmayer A, Stengele M, Kallukalam BC et al. Hypoxia in static and dynamic 3D culture systems for tissue engineering of bone. Tissue Eng Part A 2008; 14(8):1331-40.

57. Ikada Y. Challenges in tissue engineering. J R Soc Interface 2006; 3(10):589-601.

58. Genes NG, Rowley JA, Mooney DJ, Bonassar LJ. Effect of substrate mechanics on chondrocyte adhesion to modified alginate surfaces. Arch Biochem Biophys 2004; 422(2):161-7. 
59. Naujoks C, Meyer U, Wiesmann HP, Jasche-Meyer J, Hohoff A, Depprich R et al. Principles of cartilage tissue engineering in TMJ reconstruction. Head Face Med 2008; 4:3.

60. Robinson PD. Articular cartilage of the temporomandibular joint: can it regenerate? Ann R Coll Surg Engl 1993; 75(4):231-6.

61. Puelacher WC, Wisser J, Vacanti CA, Ferraro NF, Jaramillo D, Vacanti JP. Temporomandibular joint disc replacement made by tissue-engineered growth of cartilage. J Oral Maxillofac Surg 1994; 52(11):1172-7. Discussion 7-8.

62. Chen B, Sun HH, Wang HG, Kong H, Chen FM, Yu Q. The effects of human platelet lysate on dental pulp stem cells derived from impacted human third molars. Biomaterials 2012; 33(20):5023-35

63. Karaoz E, Demircan PC, Saglam O, Aksoy A, Kaymaz F, Duruksu G. Human dental pulp stem cells demonstrate better neural and epithelial stem cell properties than bone marrow-derived mesenchymal stem cells. Histochem Cell Biol 2011; 136(4):455-73.

64. Koyama N, Okubo Y, Nakao K, Bessho K. Evaluation of pluripotency in human dental pulp cells. J Oral Maxillofac Surg 2009; 67(3):501-6.

65. Mao JJ, Giannobile WV, Helms JA, Hollister SJ, Krebsbach $\mathrm{PH}$, Longaker MT et al. Craniofacial tissue engineering by stem cells. J Dent Res 2006; 85(11):966-79.

66. Moshaverinia A, Xu X, Chen C, Akiyama K, Snead ML, Shi S. Dental mesenchymal stem cells encapsulated in an alginate hydrogel co-delivery microencapsulation system for cartilage regeneration. Acta Biomater 2013; 9(12):9343-50.

\section{Endereço para correspondência:}

Fernanda Nedel

Programa de Pós-Graduação em Saúde e

Comportamento

Universidade Católica de Pelotas

Rua Gonçalves Chaves, 377, sala 411 prédio C,

Centro

96015-560 Pelotas, RS

Telefone: (53) 2128-8404

E-mail: fernanda.nedel@gmail.com

Recebido: 17/11/13. Aceito: 28/09/15. 